\title{
OS DESAFIOS PARA ADOÇÃo DA CLÁUSULA DE BARREIRA PARTIDÁRIA NO BRASIL À LUZ DO DIREITO ALEMÃO
}

\section{THE CHALLENGES FOR ADOPTION OF THE PARTY BARRIER CLAUSE IN BRAZIL UNDER GERMAN LAW}

\section{Lucas Mateus Canabarro Rodrigues}

\begin{abstract}
Mestrando em Direito pelo Programa de Pós - graduação em Direito da Universidade Federal de Santa Maria - PPGD - UFSM. Graduado em Direito pela Faculdade Metodista de Santa Maria - FAMES. Pesquisador do Centro de Estudos e Pesquisas em Direito e Internet da Universidade Federal de Santa Maria (CEPEDI), cadastrado no CNPq. E-mail: lucasmcrodrigues@gmail.com
\end{abstract}

Nina Trícia Disconzi Rodrigues

Professora adjunta no Departamento de Direito na Universidade Federal de Santa Maria e no programa de Pós-Graduação em Direito da UFSM (Mestrado), lecionando a disciplina Democracia na Sociedade em Rede. Doutora em Direito do Estado, pela Universidade de São Paulo USP. Coordenadora do Grupo de Pesquisa, cadastrado no CNPQ, Grupo de Pesquisa em Direito dos Animais, denominado GPDA, da Universidade Federal de Santa Maria. Vice-líder do Grupo de Pesquisa cadastrado no CNPq, denominado CEPEDI Centro de Estudos e Pesquisas em Direito e Internet da Universidade Federal de Santa Maria. E-mail: ninadisconzi@uol.com.br

Recebido em: 13/12/2017 Aprovado em: 30/07/2017

RESUMO: O presente trabalho versa sobre os desafios impostos a democracia brasileira diante do atual cenário de instabilidade política, dificuldades do poder executivo em formar bases de apoio no Congresso Nacional e a quantidade expressiva de partidos políticos envolvidos na operação Lava-Jato. No primeiro capítulo abordou-se a democracia no Brasil e a crise de representatividade. No segundo tópico cotejou-se o papel dos partidos políticos após a promulgação da CRFB/88 e a democracia delegativa como fator marcante no país. No terceiro e último capítulo, enfrentou-se o excesso de partidos políticos no Brasil e as dificuldades impostas na formação das bancadas de apoio no Congresso Nacional, especialmente sob o prisma de partidos nanicos sem um mínimo de representatividade capaz de justificar sua presença no Parlamento. A partir dessas premissas refletiu-se sobre a necessidade da adoção de uma cláusula de barreira partidária no Brasil, à luz do Direito Alemão. Para tanto, utilizou-se do método dedutivo, partindo-se do geral para chegar às conclusões do caso em particular do Brasil. Como resultados tem-se que a cláusula de barreira partidária é viável para uma diminuição do excesso de partidos políticos no país, com um melhoramento da representatividade no Congresso Nacional e um melhoramento do presidencialismo de coalizão, medida a qual deverá ser adotada por meio de Proposta de Emenda à Constituição.

Palavras-chave: Democracia. Partidos Políticos. Cláusula de Barreira. PEC 282/2016.

ABSTRACT: The present study deals with the challenges imposed by Brazilian democracy in the current scenario of political instability, difficulties of the executive power to form bases of support in the National Congress and the expressive number of political parties involved in the 
Lava-Jato operation. The first chapter dealt with democracy in Brazil and the crisis of representation. In the second topic, the role of political parties was checked after the enactment of $\mathrm{CRFB} / 88$ and delegative democracy as a major factor in the country. In the third and last chapter, there was an excess of political parties in Brazil and the difficulties imposed in the formation of support groups in the National Congress, especially under the prism of small parties without a minimum of representation capable of justifying their presence in Parliament. Based on these premises, it was reflected on the need to adopt a partisan barrier clause in Brazil, in light of German law. For that, the deductive method was used, starting from the general one to arrive at the conclusions of the particular case of Brazil. As a result, the party bargain clause is feasible for a reduction of the excess of political parties in the country, with an improvement of the representation in the National Congress and an improvement of the coalition presidentialism, a measure that should be adopted through Proposal of Amendment to the Constitution.

Keywords: Democracy. Political parties.Barrier Clause.PEC 282/2016.

SUMÁRIO: Introdução. 1 A democracia no Brasil e o incômodo com relação a democracia representativa. 2 Os papel dos partidos políticos na Constituição Federal de 1988 e a democracia delegativa. 3 A necessidade de uma cláusula de barreira partidária no Brasil à luz do direito alemão. Conclusão. Referências.

\section{INTRODUÇÃO}

Desde o ano de 2014 tramita a denominada "Operação Lava Jato", a qual é apontada como a maior investigação de esquemas de corrupção envolvendo políticos no Brasil, desvelando as relações obscuras entre políticos e empresas do setor de construção civil e de empresas do setor de proteína animal com a utilização do denominado "caixa dois". Tal operação causou um forte impacto no cenário político brasileiro, especialmente após a delação premiada do empresário Joesley Batista, sócio da empresa JBS, o qual declarou ter financiado por meio de caixa dois as campanhas eleitorais de 1.829 políticos ${ }^{1}$.

Nos últimos anos, nosso pais vem sendo marcado por um cenário de forte instabilidade política, para demonstrar essa problemática, registre-se o fato de um Presidente da Republica em exercício ter sido denunciado perante o Supremo Tribunal Federal, além disso, o elevado número de 28 partidos políticos até então relacionados na operação Lava-Jato. ${ }^{2}$ Logo, é muito importante o debate sobre como criar mecanismos de melhoramento e aprimoramento do sistema de representação política brasileiro, a fim de resgatar a credibilidade na democracia representativa, especialmente no papel dos partidos políticos, sendo esse o objetivo desse estudo. Atualmente há no Brasil em funcionamento 35 (trinta e cinco) partidos políticos, tornando muito difícil (ou quase impossível) promover bases de apoio político fortes no Congresso Nacional para sustentação de um governo.

A contrário sensu, a Alemanha conta atualmente com 6 (seis) estáveis partidos políticos, todos com ideologias e planos de governo claros ao eleitor, conduzindo o país a um cenário de estabilidade política e maior facilidade na formação das bancadas de apoio do governo no Parlamento. Tal feito só foi alcançado por meio da adoção da Cláusula de Barreira, a qual retirou do Parlamento Alemão o excesso partidário, garantindo um mínimo de representatividade necessária perante a população para garantir a um partido político o direito de participar do processo decisório nacional, melhorando assim a governabilidade.

\footnotetext{
${ }^{1}$ FOLHA DE SÃO PAULO. Delator da JBS diz ter pago propina a 1.829 políticos eleitos. Disponível em $<$ http://www1.folha.uol.com.br/poder/2017/05/1885698-delator-da-jbs-diz-ter-pago-propina-a-1829-politicoseleitos.shtml> Acesso em 02/mai/2017

${ }^{2}$ Disponível em <http://meucongressonacional.com/lavajato/partidos> acesso em 02/mai/2017.
} 
No Brasil, buscando um melhoramento do sistema político destaca-se dentre as propostas de Reforma Política, a PEC 282/2016 do Senado Federal, a qual busca adotar no Brasil a Cláusula de Barreira Partidária com patamar de 3\% (três por cento) dos votos nacionais para dar direito aos partidos políticos ao funcionamento parlamentar com estrutura na Congresso Nacional e participação proporcional nas comissões, possibilitando aos candidatos que não atingirem esse patamar filiarem-se a outro partido político que tenha atingido a barreira ou exercerem o seu mandato sem funcionamento parlamentar. Ainda, tal PEC limita o acesso ao fundo partidário e ao tempo de rádio e televisão aqueles partidos que não alcançarem o patamar mínimo exigido.

Diante do exposto, insurge-se o presente problema de pesquisa: a possibilidade da adoção da Cláusula de Barreira Partidária no Brasil à luz do direito alemão, analisando-se a Proposta de Emenda à Constituição 282/2016, especialmente após o julgamento das ADI's 1351/DF e 1354/DF pelo Supremo Tribunal Federal. A análise do tema proposto deu-se a partir do método de abordagem dedutivo, uma vez que é o método que parte do geral e, a seguir, desce para o particular. Este método parte de princípios reconhecidos como verdadeiros e indiscutíveis, possibilitando chegar às conclusões de maneira puramente formal, isto é, sua lógica (GIL, 2008, p.9). Dessa forma, partiu-se de conceitos gerais como democracia representativa, cláusula de barreira e representatividade, tido como verdadeiros, para se chegar as conclusões do problema do excesso de partidos políticos no Brasil.

\section{A DEMOCRACIA NO BRASIL E O INCÔMODO COM RELAÇÃO A DEMOCRACIA REPRESENTATIVA}

A definição da palavra democracia é formada por "demos" o qual significa "povo" e "kratos", o qual significa "autoridade", portanto um governo baseado na autoridade do povo e legitimado a tomar as decisões daqueles que o representam. A democracia pode ser exercida de diferentes formas, incluindo-se a democracia representativa, direta, participativa, dentre outras (MENEZES, 1999, p.267). Para Fleury (2006, p.94) no Brasil, como em outros países, a soberania popular é exercida primordialmente por meio da representação, obtida através de eleições para o poder executivo e legislativo.

Refere Fleury (2006, p.94) que cada vez mais surgem mecanismos de participação popular que demonstram a necessidade de convivência entre e a democracia representativa e a participativa. Especialmente no Brasil, a Constituição Federal de 1988 consagra o exercício da soberania no artigo primeiro, parágrafo único, ao elencar que "Todo o poder emana do povo, que o exerce por meio de representantes eleitos ou diretamente, nos termos desta Constituição." (CRFB/1988). Portanto elege a democracia representativa e a democracia direta como formas de participação política, sendo a primeira o objeto deste trabalho.

Para Bonavides (2001, p.355) "O poder é do povo, mas o governo é dos representantes, em nome do povo: eis aí toda a verdade e essência da democracia representativa.", sendo o caminho pelo qual a população governa o Estado por meio de seus representantes, os quais são eleitos por meio do voto. E o autor vai além, asseverando que a democracia representativa tem como bases a soberania popular, o sufrágio universal, a observância à Constituição, a separação dos poderes, igualdade de todos perante a lei, adesão ao princípio da fraternidade social, limitação das prerrogativas dos governantes e temporariedade dos mandatos eletivos, dentre outras. (BONAVIDES, 2001, p.294).

Schumpeter (1961, p.295) define que a democracia é um método político, um arranjo institucional para se chegarem às decisões políticas, sejam legislativas ou administrativas, por isso mesmo incapaz de ser um fim em si mesmo e justamente deve ser esse o ponto de partida para uma definição. Ainda, consigna o autor que como um sistema institucional para a tomada de decisões, os indivíduos legitimados adquirem o poder de decidir mediante uma luta competitiva 
pelos votos do eleitor, ou seja, a democracia seria um mecanismo de escolher e autorizar governos mediante competições de elites ${ }^{3}$ em eleições periódicas (SCHUMPETER, 1961, p.327).

Segundo Friedrich Müller (2003, p. 57) a ideia fundamental da democracia é a determinação normativa de convívio de um povo pelo próprio povo. Destaca o autor que não se pode ter autogoverno, já que na prática é quase inexequível, sendo que se pretende com a democracia uma auto-codificação das prescrições vigentes com base na livre competição entre interesses/opiniões divergentes, com alternativas manuseáveis de equacionamento político. Entretanto, a distância crescente entre os representantes e representados não garante mais a legitimidade de um sistema representativo que reflita a vontade do povo, demonstrando preocupações com os destinos da democracia, isolada em um conteúdo social que pode gerar um contrassenso que culmine em uma sociedade democrática injusta (TOCQUEVILLE, 1988, apud FONSECA, LACERDA E PEREIRA, 2014).

Ao discorrer sobre o tema Ferreira Filho (2012, p.46) registra o pensamento político de Montesquieu que prezava o entendimento que o homem não era capaz de tomar as decisões políticas, porém tinha capacidade para eleger aqueles que a tomariam:

A base fundamental da representação é a ideia exposta por Montesquieu de que os homens em geral não têm a necessária capacidade para bem apreciar e consequentemente bem decidir os problemas políticos. Assim, no interesse de todos, essas decisões devem ser confiadas aos mais capazes, aos representantes do povo. Mas todo e qualquer homem tem a capacidade de identificar, no seu círculo de convívio, esses que são mais capazes. Por isso, a seleção desses representantes deve ser dada a todo o povo, que a estabelecerá por meio de uma eleição [...] (Montesquieu apud Ferreira Filho, 2012, p.46).

E a seguir Ferreira Filho (2012, p.46) destaca que a "A chave da democracia representativa é obviamente a representação.", sendo que e "a representação — esse vínculo entre os governados e os governantes pelo qual estes agem em nome daqueles e devem trabalhar pelo bem dos representados e não pelo próprio - constitui um dos mais difíceis problemas do Direito Público e da ciência política.”. Nesse sentido, importante compreender os problemas da democracia representativa na atualidade, pois aprimorar o sistema é necessário, uma vez que "[...] Kautsky acha, por sua vez, que a democracia representativa seja um instrumento fundamental a ser fortalecido, mas não substituído por elementos de democracia direta ou participativa." (Kautsky apud Bobbio, 1998, p.210).

Bobbio refere a um sistema democrático em constante mutação e adaptação, este não deixa de também registrar os problemas da democracia representativa, especialmente a falta de compromisso do eleito com o eleitor após o pleito. Tal desvinculação, segundo o autor, dá-se por duas características, a saber: a) na medida em que o eleito goza da confiança do corpo eleitoral, uma vez eleito não é mais responsável perante seus eleitores sobre os atos praticados durante o seu mandato (este não é revogável) e b) não é responsável perante os seus eleitores a tutelar os interesses da sociedade civil e sim os interesses particulares de determinadas categorias (BOBBIO, 1986, p.42).

A prática de tais comportamentos pelo corpo político tem marcado as democracias contemporâneas, as quais possuem caraterísticas primordiais de eleições livres e diretas, bem como a "representação que não representa" (NOVELLI, 2011, p.245), traduzida como um distanciamento entre aquilo que é prometido no período de eleições e aquilo que é colocado em

\footnotetext{
${ }^{3}$ O termo "elite" aqui é tomado no sentido social de pessoas e grupos sociais superiores, conceito este proliferado pelos sociólogos da teoria das elites do final do século XIX, os quais entendiam que haveria em todas as esferas, em todas as áreas de ação humana, indivíduos que se destacam dos demais por seus dons, por suas qualidades superiores. Eles compõem uma minoria do restante da população - uma elite (PARETTO, 1966, p.73) os quais nesse contexto são tidoscomo os indivíduos capazes de gerir e influenciar as decisões políticas do país.
} 
prática durante o mandato. Outros autores utilizam-se do próprio termo crise de representatividade, especialmente no caso do Brasil:

O que tem se vivenciado no Brasil é a crise desse modelo. Os representantes já não representam o povo; este, por sua vez, já não se interessa pelos assuntos políticos. O número de partidos cresce, mas as ideologias continuam as mesmas, e, o poder legislativo ainda não logrou sua independência, continua a operar com preponderância do executivo (MANFREDINI, 2008, p. 25).

Segundo Comparato (2007, p.28) a crise de representatividade assume a cada dia mais indignação da população e acentua as disparidades na sociedade brasileira. Segundo o autor "O sistema de representação liberal, no Brasil, sempre foi uma fantasia retórica. Não é o povo que aparece representado nas nossas casas legislativas, e sim as classes ricas, as corporações poderosas ou os grupos de pressão mais influentes." E de fato as considerações do autor embora bastante chocantes são confirmadas pelos recentes escândalos de corrupção, especialmente após a delação da empresa JBS a qual confirmou o pagamento de propina para 1829 políticos, valores esses repassados durante as campanhas para representar os interesses da empresa nos mais variados níveis da política ${ }^{4}$.

Para Avritzer (2016, p.7) existe hoje no país uma situação de incômodo com relação à democracia representativa, especialmente a partir das manifestações de junho de 2013 e continua até o momento atual, o que pode ser aferido com a constante ida às ruas de milhões de pessoas para protestar contra os políticos e/ou serviços públicos. O aumento do número de protestos e manifestações vem se acentuando em face da Operação Lava-Jato ${ }^{5}$, a qual vem ocasionando um clima antipolítico no país, o que é preocupante, pois "não podemos prescindir dos políticos e dos partidos. Não existem alternativas reais a não ser que abdiquemos de fazer democracia" (REIS, 2017).

Mas ainda diante de todos os problemas da atualidade Bobbio entende o caminho da democracia representativa como o único caminho a ser seguido perante uma sociedade democrática, desacreditando as formas de participação política direta por meio da internet, por entender que ocasionaria a apatia política dos cidadãos:

A hipótese de que a futura computadocracia, como tem sido chamada, permita o exercício da democracia direta, isto é, dê a cada cidadão a possibilidade de transmitir o próprio voto a um cérebro eletrônico, é uma hipótese absolutamente pueril. A julgar pelas leis promulgadas a cada ano na Itália, o bom cidadão deveria ser convocado para exprimir seu próprio voto ao menos uma vez por dia. O excesso de participação, produto do fenômeno que Dahrendorf chamou depreciativamente de cidadão total, pode ter como efeito a saciedade de política e o aumento da apatia eleitoral. (BOBBIO, 1986, p.26).

E com relação a participação direta como solução para a democracia, não é apenas Bobbio que refuta essa possibilidade diante do contexto do século XXI, no qual o homem mediano tem outras preocupações a zelar no seu dia a dia, vindo a ocasionar uma apatia política o excesso de chamamento do cidadão ao processo decisório. (BONAVIDES, 2001, p.352). No mesmo sentido, Oliveira (2013, p.158) destaca que "a internet não é um substitutivo da democracia representativa

${ }^{4}$ FOLHA DE SÃO PAULO. Delator da JBS diz ter pago propina a 1.829 políticos eleitos. Disponível em <http://www1.folha.uol.com.br/poder/2017/05/1885698-delator-da-jbs-diz-ter-pago-propina-a-1829-politicoseleitos.shtml> Acesso em 02/mai/2017

5“A operação Lava Jato é a maior investigação de corrupção e lavagem de dinheiro que o Brasil já teve. Estima-se que o volume de recursos desviados dos cofres da Petrobras, maior estatal do país, esteja na casa de bilhões de reais. Soma-se a isso a expressão econômica e política dos suspeitos de participar do esquema de corrupção que envolve a companhia." Disponível em <http://lavajato.mpf.mp.br/entenda-o-caso> Acesso em 06/mai/2016.

Revista de Direito Brasileira | São Paulo, SP | v. 20 | n. 8 | p. 43-61 |Mai./Ago. 2018 
conduzindo-a para a democracia direta, pois os usuários da rede mundial de computadores não reúnem a totalidade dos eleitores", bem como não é toda a população que possuí acesso à rede e pleno domínio da tecnologia.

Bonavides (2001, p.352) também acredita ser impossível ao Estado moderno congregar todos os cidadãos em forma de democracia direta, pois "até mesmo a imaginação se perturba" em supor o tumulto que seria congregar em praça pública toda a massa do eleitorado. A seguir o autor relata que nas experiências históricas de democracia direta nas cidades-Estados Gregas os homens que reuniam-se na praça eram integralmente políticos, e não tinham a preocupação do "homem econômico" que precisa trabalhar e buscar seu sustento, chegando ao homem contemporâneo o qual é político e também econômico:

Nos sistemas compactos da ordem totalitária, o homem, perante as esferas políticas, deixa de ser politicamente "sujeito" ou "pessoa", para anular-se por inteiro como "objeto", que fica sendo, da organização social. Se o homem moderno tem apenas uma banda política do seu ser, é porque antes de mais nada aparece ele também como Homo oeconomicus. Quando dizemos homem econômico e político, estamos principalmente aludindo à possibilidade que tem o homem de conceder ou deixar de conceder mais atenção, mais zelo, mais cuidado ao trato dos assuntos políticos. (BONAVIDES, 2001, p.352).

Importante colocação de Bonavides com relação ao homem econômico, ainda mais em uma sociedade baseada na lógica de mercado onde o homem contemporâneo precisa diariamente envolver-se com questões da busca de seu sustento e, por vezes, não possui tempo suficiente disponível para participação democrática direta. Especialmente na Constituição Federal de 1988 adotou-se o Estado partidário ao elencar-se entre os princípios fundamentais o pluralismo político $^{6}$, representado pelos partidos políticos e suas respectivas ideologias, uma vez que o homem moderno é representado no processo de decisão política por eles. É o que se passa a debater.

\section{OS PAPEL DOS PARTIDOS POLÍTICOS NA CONSTITUIÇÃO FEDERAL DE 1988 E A DEMOCRACIA DELEGATIVA}

A partir da Constituição Federal de 1988 deu-se ainda mais espaço e liberdade aos partidos políticos como legitimados para exercer a representação, devido à grande desconfiança do constituinte em relação ao legislador infraconstitucional, além de demonstrar a intenção de salvaguardar uma série de reivindicações e conquistas contra uma eventual supressão de direitos pelos poderes constituídos (SARLET, 2012, p.64), fruto do trauma que passou o Brasil durante o período da ditadura militar e da marginalização dos partidos que eram contra o regime. Tal importância fica clara ao verificar que o constituinte dedicou capítulo próprio no texto constitucional para eles, bem como dispôs sobre a liberdade de criação, fusão, incorporação e extinção de partidos políticos, resguardados a soberania nacional, o regime democrático, o pluripartidarismo, os direitos fundamentais da pessoa humana (Art. 17, CRFB/88) ${ }^{7}$.

\footnotetext{
${ }^{6}$ Art. $1^{\circ}$ A República Federativa do Brasil, formada pela união indissolúvel dos Estados e Municípios e do Distrito Federal, constitui-se em Estado Democrático de Direito e tem como fundamentos:

I - a soberania;

II - a cidadania

III - a dignidade da pessoa humana;

IV - os valores sociais do trabalho e da livre iniciativa;

V - o pluralismo político.(grifo dos autores).

${ }^{7}$ Art. 17. É livre a criação, fusão, incorporação e extinção de partidos políticos, resguardados a soberania nacional, o regime democrático, o pluripartidarismo, os direitos fundamentais da pessoa humana e observados os seguintes preceitos: Regulamento
} 
E o legislador constitucional foi além, ao erigir no Art. 17, § único, da CRFB/88 que

É assegurada aos partidos políticos autonomia para definir sua estrutura interna, organização e funcionamento e para adotar os critérios de escolha e o regime de suas coligações eleitorais, sem obrigatoriedade de vinculação entre as candidaturas em âmbito nacional, estadual, distrital ou municipal, devendo seus estatutos estabelecer normas de disciplina e fidelidade partidária.

Portanto é um fato notório a preocupação do constituinte com o destaque dos partidos políticos no movimento de redemocratização do Brasil em 1988, os quais ganharam amplo leque de direitos e garantias sendo que

A adoção desse modelo iniciou-se no Brasil com a Constituição de 1946, mas se completou com a Constituição de 1967, em particular com a Emenda n. 1/69. Caracteriza-se ele pela inserção nas Constituições de normas que, definindo as funções do partido político, lhe concedem direitos, especialmente em matéria eleitoral e parlamentar, ao mesmo tempo que lhe conferem garantias. (FERREIRA FILHO, 2012, p.49)

Nas palavras de Caggiano (2012, p.403) o maior avanço no desenvolvimento da democracia brasileira deve ser atribuído, sem dúvida, ao sistema de partidos instalado pelo constituinte, o qual inviabiliza a presença de candidatos independentes e contribui para um fortalecimento significativo, posicionando os partidos como peça imprescindível para a operação eleitoral. Conforme a autora, os partidos de forma isolada ou por coligação são os responsáveis pelo registro das candidaturas que apresentam para a disputa dos votos, bem como os responsáveis pela campanha e divulgação dos postulantes. Assim, os partidos assumem o papel de detentores dos mandatos eletivos conquistados sob sua legenda.

Porém, se de um lado houve uma imensa preocupação com relação ao posicionamento dos partidos políticos no cenário da Constituição Federal de 1988 com toda a sua importância para uma eficaz democracia representativa no Brasil, por outro lado não há que se esquecer de que os escritores políticos da literatura antipartidária não estabeleciam a distinção entre partidos políticos e facções (BONAVIDES, 2001, p.453). Para Madison (apud Bonavides, 2001, p.454) é um progresso o reconhecimento dos partidos políticos aparecerem separados das facções, porém, se o partido é o lado positivo a facção é o lado negativo da participação política organizada.

Especialmente no caso do Brasil é impossível uma candidatura sem vinculação partidária, pois o Art. $14, \S 3^{\circ}, \mathrm{V}^{8}$, estabelece como condição de elegibilidade a filiação partidária, sendo um caminho obrigatório para a democracia representativa os partidos políticos. Nas palavras de Mezzaroba (2008, p.40) a democracia brasileira caracteriza-se por ser uma

I - caráter nacional;

II - proibição de recebimento de recursos financeiros de entidade ou governo estrangeiros ou de subordinação a estes;

III - prestação de contas à Justiça Eleitoral;

IV - funcionamento parlamentar de acordo com a lei.

$\S 1^{\circ}$ É assegurada aos partidos políticos autonomia para definir sua estrutura interna, organização e funcionamento e para adotar os critérios de escolha e o regime de suas coligações eleitorais, sem obrigatoriedade de vinculação entre as candidaturas em âmbito nacional, estadual, distrital ou municipal, devendo seus estatutos estabelecer normas de disciplina e fidelidade partidária. (Redação dada pela Emenda Constitucional nº 52, de 2006)

$[\ldots]$

${ }^{8} \S 3^{\circ}$ São condições de elegibilidade, na forma da lei:

I - a nacionalidade brasileira;

II - o pleno exercício dos direitos políticos;

III - o alistamento eleitoral;

IV - o domicílio eleitoral na circunscrição;

V - a filiação partidária; [...] (grifo nosso).

Revista de Direito Brasileira | São Paulo, SP | v. 20 | n. 8 | p. 43-61 |Mai./Ago. 2018 
democracia representativa partidária, portanto não admite candidaturas avulsas ou desvinculadas das ideologias político-partidárias.

Por outro prisma, se de um lado é inegável a importância dos partidos políticos para a democracia brasileira; de outro é assustador o número de partidos políticos envolvidos na operação Lava-jato, deflagrada em 17 de março de 2014, desvelando-se um lado obscuro das relações entre os partidos políticos e as empreiteiras, envolvendo aproximadamente 28 partidos até então relacionados na operação ${ }^{9}$. Tais acontecimentos tornaram latentes os debates sobre como criar mecanismos de melhoramento e aprimoramento do sistema de representação política brasileiro, de modo a resgatar a credibilidade na democracia representativa.

Para Avritzer (2016, p.92) o aumento da divulgação dos escândalos de corrupção isso impactou diretamente na percepção da sociedade sobre o fenômeno, sendo que $73 \%$ dos brasileiros a consideram um fenômeno muito grave. Destaca o autor que o sistema político brasileiro passou por poucas alterações desde o processo de elaboração da Constituição Federal de 1988, sendo que a opção do constituinte originário pelo sistema proporcional acabou criando o chamado "Presidencialismo de coalisão" 10 e desde então as negociações para a conquista de maiorias tem como moeda de troca no Congresso Nacional os recursos públicos alocados pela União ou a distribuição de cargos nos ministérios. Tais fatores são o ambiente propício para a proliferação da corrupção e caixa dois, levando a diminuição da confiança da população no sistema e sua legitimidade.

Segundo O’ Donnell (apud Streck e De Morais, 2014, p.92) no Brasil e em alguns países da América Latina recentemente saídos de regimes autoritários a democracia funda-se em um tipo de modelo de "democracia delegativa", sendo que para fundar sua tese o cientista político desenvolveu o argumento que

As democracias delegativas se fundamentam em uma premissa básica: quem ganha a eleição presidencial é autorizado a governar o país como lhe parecer conveniente, e, na medida em que as relações de poder existentes permitam, até o final de seu mandato. O presidente é, assim, a encarnação da nação, o principal fiador do "interesse maior da nação", que cabe a ele definir. O que ele faz no governo não precisa guardar nenhuma semelhança com o que ele disse ou prometeu durante a campanha eleitoral - afinal, ele foi autorizado a governar como achar conveniente. (O’ Donnell apud Streck e De Morais, 2014, p.92).

E segue o autor destacando que essas democracias utilizam o artifício das eleições em dois turnos, isto porque, se as eleições do primeiro turno não geram diretamente uma maioria, o segundo turno terá que gerá-la, para ocasionar o mito da "deleção legítima". Mais ainda, a democracia delegativa é fortemente individualista ${ }^{11}$, que pressupõe eleitores que escolhem o candidato e não o partido, independente de suas identidades e filiações. Por tal motivo, destaca o autor que essas eleições são marcadas por processos altamente emocionais, sem levar em conta as restrições impostas pelos outros poderes para governar ao país, levando a um jogo de debates de resultado absolutamente zero (O’ Donnell apud Streck e De Morais, 2014, p.93).

\footnotetext{
${ }^{9}$ Disponível em <http://meucongressonacional.com/lavajato/partidos > acesso em 02/mai/2017.

${ }^{10}$ Termo desenvolvido pelo cientista político Sérgio Abranches para definir a lógica do presidencialismo vivenciado no Brasil marcado por combinar o sistema eleitoral proporcional, o multipartidarismo e o 'presidencialismo imperial', organizando o Poder Executivo com base em grandes coalizões e havendo a necessidade de intensas negociações com o Poder Legislativo para a aprovação das políticas desenvolvidas (ABRANCHES, Sérgio, 1988, p.10).

${ }^{11}$ Sobre o tema Sérgio Resende de Barros cunhou o termo "presidentismo", pois em verdade não temos um "Presidente da República", mas uma "República de Presidente" caracterizada na exagerada concentração de poderes nas mãos do Presidente da República, inclusive com o dever-poder de legislar, ocasionando conflitos de poderes que atormentam o Estado, especialmente com o Poder Legislativo (BARROS, 1971, p.67).
}

Revista de Direito Brasileira | São Paulo, SP | v. 20 | n. 8 | p. 43-61 |Mai./Ar. 2018 
Se de um lado os partidos políticos enfrentam atualmente uma série de problemas em relação a sua legitimação para exercer a democracia representativa, ainda mais diante do cenário atual do escândalo de corrupção da operação Lava-Jato, sendo de um lado daninhos; de outro são o único caminho a ser seguido, porque servem para se repensar a estrutura da democracia sem que outra coisa os possa substituir nesse papel; mas, por outro possuem um certo veneno capaz de reduzi-los a nada, ou, ao menos, deformá-los ( DUVERGER, 1970, p.273).

Assim, buscando-se um aprimoramento da democracia representativa e, sobretudo dos partidos políticos, passa-se a discutir a necessidade da adoção de uma cláusula de barreira partidária no Brasil, especialmente após o julgamento pelo Supremo Tribunal Federal das ADI's 1351/DF e 1354/DF, as quais julgaram tal instituto inconstitucional.

\section{A NECESSIDADE DE UMA CLÁUSULA DE BARREIRA PARTIDÁRIA NO BRASIL À LUZ DO DIREITO ALEMÃO}

Atualmente no Brasil há em funcionamento com registro perante o Tribunal Superior Eleitoral 35 (trinta e cinco) partidos políticos, das mais diversas siglas, tamanhos e bases ideológicas. Ainda, há outros 63 (sessenta e três) partidos em processo de formação perante a corte eleitoral, dos quais se destacam o Partido Democrata Cristão - PDC, Partido da Segurança Pública e Cidadania - PSPC, Partido Humanitário Nacional - PHN, dentre outros em tramitação para obterem seus registros junto ao tribunal (TSE, 2017). Doutra banda, se é considerável o número de partidos em funcionamento com registro e aqueles em processo de formação para obterem registro perante o TSE, também é considerável o número de partidos políticos relacionados na operação Lava-Jato, dos quais se aponta que 28 (vinte e oito) partidos políticos receberam doações eleitorais das empresas relacionadas na operação (MeuCongressoNacional.com, 2017).

O excesso de partidos políticos no Brasil é um reflexo eminente sistema eleitoral proporcional $^{12}$ para eleições do Poder Legislativo, o qual tende a reduzir a quase nada o fenômeno da sub-representação, pois o número de votos válidos é dividido pelas cadeiras a serem ocupadas na câmara, obtendo-se o quociente eleitoral, o qual é a proporção que cada partido conseguirá eleger de seus representantes (FERREIRA FILHO, 2001, p.174). A principal virtude da representação proporcional está na sua capacidade de espelhar um Legislativo com todas as opiniões relevantes existentes na sociedade, bem como garantir uma equidade matemática do número de votos que um partido político recebeu e a sua representação na casa legislativa (NICOLAU, 2004, p.37).

Entretanto é necessário debater até qual ponto o sistema eleitoral proporcional no Brasil favorece a multiplicação de partidos políticos, possibilitando a criação de partidos sem qualquer importância e cuja única finalidade é tirar proveito de algum possível poder de barganha em votações e eleições importantes (SILVA, 1999, p.165), o que vem sendo corroborado pelos escândalos da operação Lava-Jato. Relata o autor que é preciso esclarecer que a existência dos partidos políticos isoladamente não pode ser tomada como um problema, pois a sociedade é heterogênea e a representação de diversos setores sociais no Congresso Nacional é o espelhamento dessa sociedade. Logo, o que se discute nesse trabalho é até qual ponto há um mínimo de representatividade de um partido político para ocupar cadeiras no Poder Legislativo.

No Brasil a quantidade excessiva de partidos políticos está prejudicando a verdadeira essência da representatividade, marcada pela presença de uma vasta quantidade de pequenos partidos meramente interessados no poder de barganha em grandes votações. Tal situação é preocupante para a democracia brasileira, pois a sobrevivência de partidos políticos sem um

\footnotetext{
${ }^{12}$ No sistema proporcionalestabelece-se uma proporção entre o número de votos recebidos pelos partidos eo número de vagas eleitorais que ele obtém, sendo considerados eleitos oscandidatos mais votados pertencentes aos seus quadros. Este sistema é adotado no Brasil para as eleições no Legislativo (Streck; De Moraes, 2014, p.183).
}

Revista de Direito Brasileira | São Paulo, SP | v. 20 | n. 8 | p. 43-61 |Mai./Ago. 2018 
mínimo de representatividade é muitas vezes garantida pelo sistema eleitoral proporcional. Representatividade significa um mínimo de apoio popular que garanta o acesso à Câmara dos Deputados, de forma a justificar a presença daquele partido na casa legislativa (SILVA, 1999, p.166).

No Brasil há uma significativa presença dos chamados "partidos nanicos" ou "partidos de aluguel" os quais favorecidos pelo sistema eleitoral conseguem manter seus espaços no Congresso Nacional. Portanto, diante da quantidade de partidos nanicos em funcionamento, os quais sobrevivem graças ao sistema proporcional e não necessariamente atendem ao conceito de representatividade, portanto não decorrentes da fragmentação social, mas sim da fragilidade do sistema eleitoral, necessário se faz a criação de mecanismos para barrar o acesso deles ao Congresso Nacional, o que pode ser solucionado com a cláusula de barreira (SILVA, 1999, p.166).

Segundo Gomes (2016, p. 187) há excessiva presença no Brasil dos formados pelos chamados "partidos nanicos" ou "partidos de aluguel", de diminuta expressão no contexto sociopolítico, e cuja sobrevivência se deve ao aluguel de suas legendas, daí a expressão "partidos de aluguel". Refere o autor que, na verdade não passam de pequenas oligarquias a serviço de uma ou outra personalidade, fechadas, pois, à renovação e ao intercâmbio de ideias. Há de se destacar, que embora sejam pequenos grupos bastante fechados, estes possuem acesso aos recursos do fundo partidário como qualquer outro partido, bem como tempo de rádio e televisão.

Para corrigir o problema do excesso de partidos no Brasil sem representatividade é necessário pensar o problema a partir da fonte: como partidos nanicos sem expressividade conseguem eleger representantes? Segundo Silva (1999, p.166) uma das fragilidades do sistema eleitoral atual é a autorização pelo código eleitoral de coligações de dois ou mais partidos para o registro de candidatos em comum, contabilizando-se os votos como se fosse apenas um único partido. Segundo o autor, isso possibilita que partidos políticos com baixíssimo grau de representatividade, os quais não conseguiriam eleger candidatos sozinhos, acabem atingindo o quociente eleitoral e chegando ao Poder Legislativo. Ao chegar ao Congresso Nacional tais partidos, embora com baixa influência no processo decisório, acabam adquirindo as prerrogativas dos demais partidos, tal como acesso ao fundo partidário e tempo de televisão.

Segundo Tavares (2003, p.342) a criação de novos partidos políticos tem sido estimulada basicamente por dois arranjos institucionais: a) o regimento interno da Câmara dos Deputados atribui que o partido que possuí o mínimo de um centésimo de membros daquela casa o direito a instalações, empregos, assistência e todos os privilégios que são concedidos aos partidos nela representados (inclusive o poder de barganhar cargos com o Poder Executivo); e b) também conseguem acesso ao tempo de propaganda eleitoral gratuita, no rádio e na televisão, o que possibilita a negociação desse tempo com outros partidos em futuras coligações. São partidos inexpressivos sob o prisma da representação, porém com poder de barganha e assentamento estrutural de cargos como qualquer outro grande partido no Legislativo.

Para Sartori (1982, p.146) ao enfrentar a questão propõe a adoção de um critério de irrelevância em relação aos partidos políticos. Para tanto, o autor parte do pressuposto que a força de um partido é, primordialmente, sua força eleitoral e em seguida propõe para a solução do impasse que é possível extrair da contabilidade da relevância política os partidos que não tem potencial de coalização. Em suma, um partido que por seguidas eleições não consegue sucesso suficiente para ser considerado um aliado essencial nas coalizões governamentais seria politicamente irrelevante. Ainda, pode-se dizer o mesmo dos partidos que não alcançam um resultado eleitoral suficiente necessário para conduzir uma mudança na direção das competições partidária, posicionando-se como situação ou oposição.

Para um controle do excesso de partidos políticos alguns países utilizam a chamada cláusula de barreira, também conhecida por cláusula de bloqueio ou de exclusão, a qual nas palavras de Orides Mezzaroba (2003, p.301) é “o mecanismo previsto em dispositivo legal que 
impede a existência ou a representação parlamentar da agremiação partidária que não conte com o apoio de um determinado número ou percentual de eleitores". Por meio da cláusula de barreira exclui-se com o decorrer do tempo a existência dos partidos nanicos/ partidos de aluguel, os quais contam com baixíssima representação no parlamento e geralmente representam posições extremistas da sociedade. A cláusula de exclusão foi adotada em outros países como Alemanha, Grécia e Argentina, conduzindo esses países a governos mais estáveis, pois o excesso de fragmentação partidária prejudica a governabilidade e a estabilidade do sistema político (CASTRO, p.188, 2006).

E nesse prisma que se insurge a crítica sobre o excesso de partidos políticos no Brasil e as dificuldades em compor as bancadas de apoio no Congresso Nacional, conduzindo o país a um cenário de ingovernabilidade. Sob o prisma das leis de Duverger (1970, p.393) a estrutura interna dos partidos pode modificar profundamente o estado das coisas, pois os partidos políticos nanicos que possuem base financeira fraca vivem perpétuas dificuldades financeiras, portanto várias vezes sensíveis a candidatos "populares" os quais poderão angariar significativa quantidade de votos para perpetuar a existência do partido no parlamento, porém sem vinculação com o programa daquela sigla.

Ferreira Filho (1966, p.114) faz uma severa crítica à multiplicação infinita de partidos políticos no Brasil, estimulados pelo sistema eleitoral proporcional, formando novos pequenos partidos políticos, novas pequenas facções, pequenos grupos inexpressivos, porém às vezes perigosos. Destaca o autor que tais grupos são mais facilmente corrompidos pelo dinheiro ou conquistados por uma camarilha ${ }^{13}$, daqueles que defluem interferências indevidas na formação do processo de vontade geral. Por fim, refere Ferreira filho (1966, p.114) que o multipartidarismo é um obstáculo ao funcionamento do regime parlamentar, pois se nenhum dos partidos tem maioria absoluta, necessariamente os governos serão de coalisão e, em consequência, quase tíbios e instáveis.

Nogueira Filho (2007, p.241) também destaca que os sistemas pluripartidários, em especial em suas versões mais extremas, podem influenciar na governabilidade, pois exigem a formação de governos dos coalisão, forçando-os a deixarem de lado o respeito aos temas políticos para formarem suas bases no Congresso Nacional. Destaca o autor que, por outro lado, países dotados de apenas duas siglas partidárias podem carecer de programas diferenciados, caso em que as propagandas eleitorais deixam de esclarecer aos eleitores das propostas deles. Com isso, não se quer dizer que deve ser adotado no Brasil o bipartidarismo, mas sim chegar a um consenso mínimo do significado de representatividade, capaz de manifestar-se no Congresso Nacional com partidos de posturas políticas distintas, bem definidas, capazes de formar governos de coalizão minimamente estáveis.

Esse excesso de partidos no Brasil e total personalização da política vêm prejudicando a democracia representativa e causando confusão entre os eleitores, os quais sequer conseguem distinguir as diferenças entre os programas partidários existentes, afinal de contas atualmente são 35 partidos em funcionamento. Ensina Ferreira Filho (2012, p.60) que o elemento pessoal na política continua a preponderar, impulsionado pela valorização dos veículos de massa que destacam as personalidades em prol dos ideais. Destaca o autor que no Brasil há um desapreço pelos programas partidários, visto como mero "blábláblá" que ninguém, inclusive os candidatos levam a sério.

E nessa mesma linha pertinentes se mostram os ensinamentos proferidos no voto do Ministro Luís Roberto Barroso nos autos da ADI ${ }^{\circ}$ 5.081/DF ao destacar sobre o contexto atual dos partidos políticos:

\footnotetext{
${ }^{13}$ Camarilha: Grupo de pessoas que desfrutam da convivência com uma autoridade, um governante ou pessoa importante e tentam influir nas suas decisões (MICHAELIS, 2017).
} 
O sistema partidário é caracterizado pela multiplicação de partidos de baixa consistência ideológica e nenhuma identificação popular. Surgem, assim, as chamadas legendas de aluguel, que recebem dinheiro do Fundo Partidário - isto é, recursos predominantemente públicos - e têm acesso a tempo gratuito de televisão. O dinheiro do Fundo é frequentemente apropriado privadamente e o tempo de televisão é negociado com outros partidos maiores, em coligações oportunistas e não em função de ideias. A política, nesse modelo, afasta-se do interesse público e vira um negócio privado. (BRASIL, 2015).

Nas palavras de Ferreira Filho (2001, p.187) o sistema eleitoral puro adotado no Brasil gera um "multipartidarismo excessivo", termo que o autor utiliza para determinar países onde há existência de mais de cinco partidos políticos. Assevera o autor que o multipartidarismo enfraquece os partidos políticos, dando espaço para que outros interesses venham a participar das decisões políticas. Na sequência, Ferreira Filho (2001, p.188) destaca que o grande número de partidos políticos obscurece e dificulta a vontade popular pois, se a democracia presume um governo pelo povo a força decisiva para tal manifestação deve ser desejada e buscada. Defende o autor que os partidos políticos sejam livres para concorrer as eleições, vedadas as coligações, estando a deriva de sua própria sorte para angariar uma representação suficiente no Parlamento. É o que reclama a democracia para a decisão política, em prol do povo e também da governabilidade, estando fora do processo decisório aqueles partidos sem um mínimo de representatividade.

Neste ponto consigna-se que a baixíssima representatividade de alguns partidos políticos que continuam ativos graças à inexistência de uma cláusula de barreira vem levando o Congresso Nacional e os próprios partidos políticos a um cenário de descrédito perante a população, uma vez que conforme pesquisa IBOPE por 3 (três) anos consecutivos ( 2009 a 2011) estes ficaram respectivamente na última e penúltima posições no índice de Confiança Social (ICS) do brasileiro, perdendo inclusive nesse critério para os bancos, meios de comunicação e empresas (TAVARES, 2012, p.3), o que se denota como assustador uma vez que os partidos representam (ou deveriam representar) uma parcela significativa da população que lhes concedeu votos para representa-los no Congresso Nacional.

Importante destacar que o Brasil já teve uma previsão de cláusula de barreira, por meio da lei 9.096/95, a qual trouxe a previsão para a partir do ano de 2005 os partidos políticos que não atingissem $5 \%$ (cinco por cento) dos votos gradualmente deixariam de existir, pois os seus candidatos eleitos teriam duas opções: mudar de partido (o que afetaria a representação política e aumenta a desproporcionalidade na distribuição de cadeiras) ou trabalhar com uma série de limitações, de forma isolada e sem visibilidade (CASTRO, 2006, p.190). Assevera a autora que a cláusula de barreira significaria uma morte gradual aos partidos políticos de aluguel, já que a tendência natural seriam eles juntarem-se a partidos maiores ou fundirem-se com outros pequenos partidos para formar um único partido.

Entendeu o Supremo Tribunal Federal no bojo das ADI's 1351/DF e 1354/DF que os dispositivos impugnados da lei 9.096/95 que estabeleciam a cláusula de barreira violavam o art. $1^{\circ}$, V, da CRFB/88 o qual prevê como um dos fundamentos da República o pluralismo político; No mais, entendeu-se naquela ocasião violação ao art.17, da CRFB/88 que estabelece a liberdade de criação, fusão, incorporação e extinção dos partidos políticos, não cabendo ao legislador ordinário tratar de matéria a ponto de esvaziarem-se os princípios constitucionais, de modo a inviabilizar a atuação de bancadas minoritárias e impedindo os respectivos deputados de comporem a Mesa Diretiva e as comissões. Restou consignado naquelas ações que sob o ângulo da razoabilidade, seriam inaceitáveis os patamares de desempenho e a forma de rateio concernente à participação no Fundo Partidário e ao tempo disponível para a propaganda partidária adotados pela lei. (BRASIL, 2006). 
Ainda, entendeu o Supremo Tribunal Federal naquela ocasião que relativamente ao Art.17, IV, da CRFB/ $88^{14}$ que a previsão legal quanto à competência do legislador ordinário para tratar de funcionamento parlamentar não deve ser tomada a ponto de se esvaziar os princípios constitucionais, notadamente o revelador do pluripartidarismo e inviabilizar, por completo, o funcionamento das bancadas desses partidos minoritários, impedindo os deputados de comporem a Mesa Diretiva das comissões. (BRASIL, 2006).

E nesse ponto foi acertada a decisão do Supremo Tribunal Federal, especialmente a partir da premissa que a $\mathrm{CRFB} / 88$ regulamentou os partidos políticos como instrumentos necessários e importantes para a preservação do Estado Democrático de Direito, afirmando a liberdade de criação, fusão, incorporação e extinção dos partidos políticos, resguardados a soberania nacional, o regime democrático e os preceitos de caráter nacional; proibição de recebimento de recursos financeiros e entidades ou governo estrangeiros ou de subordinação a estes; bem como ao final prestação de contas a justiça eleitoral e funcionamento parlamentar nos moldes da legislação (MORAES, 2009, p.264).

No entanto, não significa dizer que a cláusula de barreira partidária não possa ser adotada no Brasil, especialmente por meio de Proposta de Emenda à Constituição. Restou consignado no cerne daquele julgamento que o cerne da inconstitucionalidade dos dispositivos da lei 9.096/95 foi justamente a invasão pelo legislador ordinário, infringindo de matéria que foi disciplinada pelo constituinte originário, violando princípios constitucionais, especialmente o da proporcionalidade. Segundo Silva (p.16, 2005) a CRFB/88 com relação à disciplina dos partidos políticos é minimalista, garantindo ampla autonomia de organização e funcionamento aos partidos políticos. Portanto seria um absurdo uma legislação ordinária vir a regulamentar uma matéria constitucional de tamanha sensibilidade, a qual não deixou espaço para regulamentação na legislação infraconstitucional.

O único caminho possível para adoção da Cláusula de Barreira no Brasil de modo a frear a exagerada fragmentação dos partidos políticos é por meio de Proposta de Emenda à Constituição, pois diante do posicionamento do STF nas ADI 1351/DF e ADI 1354/DF legislação infraconstitucional não poderá regulamentar a matéria. Atualmente está pronta para ir às discussões do plenário da Câmara dos Deputados a PEC 282/2016, originária do Senado Federal, a qual busca alterar a Constituição Federal para vedar as coligações nas eleições proporcionais, disciplinar a autonomia dos partidos políticos e estabelecer normas sobre fidelidade partidária e funcionamento parlamentar dos partidos políticos.

Tal Proposta de Emenda à Constituição prevê uma substancial mudança no Art.17 e incisos da $\mathrm{CF} / 88$, especialmente ao prever no Art.17, §2º ao instituir uma Cláusula de Barreira de $3 \%$ (três por cento) dos votos válidos, distribuídos em pelo menos 14 (quatorze) unidades da Federação, com um mínimo de $2 \%$ (dois por cento) em cada uma delas:

$\S 2^{\circ}$ Os partidos políticos, após adquirirem personalidade jurídica, na forma da lei civil, registrarão seus estatutos no Tribunal Superior Eleitoral, e terão direito a funcionamento parlamentar aqueles que obtiverem, nas eleições para a Câmara dos Deputados, no mínimo 3\% (três por cento) dos votos válidos, distribuídos em pelo menos 14 (quatorze) unidades da Federação, com um mínimo de 2\% (dois por cento) dos votos válidos em cada uma destas.

E na sequência a PEC prevê a alteração do Art.17, §3º da CRFB/88 para definir que somente os partidos políticos com funcionamento parlamentar terão direito a participar da

\footnotetext{
${ }^{14}$ Art. 17. É livre a criação, fusão, incorporação e extinção de partidos políticos, resguardados a soberania nacional, o regime democrático, o pluripartidarismo, os direitos fundamentais da pessoa humana e observados os seguintes preceitos:[...]

IV - funcionamento parlamentar de acordo com a lei. (grifo nosso). [...]
} Revista de Direito Brasileira | São Paulo, SP | v. 20 | n. 8 | p. 43-61 |Mai./Ago. 2018 
distribuição dos recursos do fundo partidário, bem como acesso ao tempo gratuito de rádio e televisão. Também há previsão de alteração do Art.17, §6º da CRFB/88 para permitir ao candidato eleito, sem funcionamento parlamentar, a possibilidade de filiação a outro partido com funcionamento parlamentar, sem perda do mandato, não sendo essa filiação considerada para fins de distribuição dos recursos do fundo partidário e tempo de propaganda política gratuita ou então seguir o seu mandato sem funcionamento parlamentar.

Tal Proposta de Emenda à Constituição representa um dos pontos da agenda da reforma política no Brasil para melhorar a democracia representativa, pois com o decorrer do tempo forçará os partidos nanicos a procurarem agremiações maiores ou resistirem em funcionamento mesmo com restrições no Congresso Nacional, até atingirem um grau mínimo de representatividade de modo a ter direito ao funcionamento parlamentar. Embora fortemente criticada pelos partidos nanicos o Brasil precisa enfrentar e debater essa questão, de modo a frear a multiplicação descontrolada de partidos políticos, em prol de uma salutar democracia representativa e um mínimo de governabilidade.

Ainda, consigna-se que a PEC 282/2016 do Senado Federal sofreu significativas alterações na Câmara dos Deputados, especialmente ao passar pela comissão especial destinada a proferir parecer sobre o tema, a qual incluiu no projeto uma regra de transição para as eleições de 2018, 2022 e 2026, incluindo uma cláusula de barreira de 1\%,1,5\% e 2,5\%, respectivamente, até atingir o patamar de $3 \%$ previsto originariamente. Ainda, tal parecer incluiu ao projeto a possibilidade dos partidos políticos que não a atingirem o patamar mínimo manterem seu funcionamento parlamentar, desde que conquistem 18 cadeiras na Câmara dos Deputados, distribuídos em pelo menos um terço das unidades da federação, também com regra de transição de 2018 a 2026, partindo do patamar de 12 deputados federais eleitos para as próximas eleições (BRASIL, 2017).

No mais, o substitutivo a PEC 282/2016 apresentado na comissão especial da câmara também trouxe a possibilidade de união dos partidos políticos, sendo que aqueles que não atingirem a cláusula de barreira poderão se unir em forma de federação para alcançar o patamar exigido. Ainda, o substitutivo reforça a possibilidade do candidato eleito sem funcionamento parlamentar filiar-se a outro partido que tenha atingido a cláusula de barreira, não contabilizando essa união para distribuição do tempo de televisão e rádio, bem como para o acesso ao fundo partidário (BRASIL, 2017).

Neste ponto cita-se o caso da Alemanha (país o qual adota a cláusula de barreira) desde 1949 e buscou com isso evitar novas situações de fragmentação partidária (a exemplo de 1920 quando 17 partidos chegaram ao Parlamento, inviabilizando a formação da base de governo) e que, dentre outros fatores, motivaram a queda da república de Weimar e a ascensão do nazismo. Para evitar tais situações, impedir a chegada de partidos extremistas ao Parlamento e garantir a estabilidade político-institucional da nação optou-se na Alemanha pela adoção da Cláusula de Barreira, no percentual de 5\% (cinco por cento) no percentual de votos nacionais ou a conquista de pelo menos 3 (três) mandatos majoritários em qualquer distrito eleitoral do país ( PONTES; VAN HOLTHE, 2015, p.23).

Especialmente na Alemanha, após a adoção da cláusula de barreira no patamar de 5\% (cinco por cento) a nação foi conduzida para um cenário de maior estabilidade política e governabilidade, diminuindo-se o número de partidos políticos para 6 (seis): CDU, CSU, SPD, Partido Verde, "A Esquerda" e Partido Liberal - FDP. Entretanto, surpreendentemente no ano de 2015 os alemães tiveram a surpresa de uma taxa inédita de desconsideração de votos dados a partidos políticos pequenos eliminados pela cláusula de barreira, cerca de $15 \%$ (quinze por cento) de todos os votos válidos da Alemanha foram descartados (PONTES; VAN HOLTHE, 2015, p.24), uma fenômeno recente e ainda não bem compreendido por especialistas.

Segundo Paulo Bonavides (2001, p.252) a Cláusula de Barreira adotada na Alemanha vêm contribuindo para a proteção do regime democrático e contra a ameaça de organizações 
político-ideológicas extremistas. Conforme o autor, embora receba severas críticas ela garante uma representação proporcional de partidos políticos fortes, em harmonia com a ordem estabelecida. É isto que se busca nesse momento para o Brasil, assolado pelos escândalos da Operação Lava-Jato, especialmente diante da imensa quantidade de partidos políticos envolvidos em casos de corrupção.

Quanto à crítica daqueles que acreditam a Cláusula de Barreira prejudica o sistema proporcional na representação a experiência na Alemanha demonstrou justamente o contrário. Nas palavras de Unglaub (1995, p.27) a cláusula de barreira não deixa dúvida quanto a garantir um processo eleitoral como formador da vontade do povo, sendo que ela contribuiu fundamentalmente para a concentração dos partidos e a estabilidade da ordem na Alemanha, inclusive com partidos menores várias vezes ultrapassando a barreira dos 5\% (cinco por cento), comprovando que não apenas os grandes obtêm êxito nas eleições.

Nas palavras de Leão Viana (2006, p.21) um dos principais benefícios da Cláusula de Barreira adotada pela Alemanha foi contribuir para a criação de partidos fortes, permanentes, capazes de manter uma relação ideológica com seu eleitorado, não criando, ao mesmo tempo, um sistema bipartidário. Ainda, destaca o autor que o próprio histórico das coalizões governamentais demonstra que todos os partidos atualmente representados no Parlamento já estiveram tanto no governo como na oposição, o que reforça a ideia que a cláusula não congela o sistema político em benefício dos grandes.

Por fim, diante do atual cenário de instabilidade política no Brasil, marcado fundamentalmente pelas dificuldades do Poder Executivo em formar bases de apoio no Congresso Nacional, fator este que acaba ocasionando um Legislativo fragmentado e desacreditado perante a população em razão dos escândalos de corrupção pela compra de votos, imperiosas são as palavras de Leonardo Avritzer:

Não temos dúvida de que estamos no final de um ciclo no que diz respeito à democracia brasileira. Estamos encerrando um ciclo em relação às características do governo de esquerda que existe no Brasil desde 2003; estamos encerrando um período no que diz respeito ao presidencialismo de coalizão e sua capacidade de ancorar o sistema político e da capacidade do estado de financiálas sem gerar fortes conflitos distributivos. (AVRITZER, 2016).

$\mathrm{Na}$ busca por esse novo caminho de relações do Poder Executivo com o Poder Legislativo é que se insurge a Cláusula de Barreira, pois ela se adotada no Brasil garantiria uma gradual redução dos partidos políticos (atualmente 35 legendas com registro perante o TSE), como no caso da Alemanha que conta atualmente com 6 (seis) grandes partidos. É necessário fortalecer os partidos políticos, e esse fortalecimento perpassa pela exclusão daqueles que não contam com um mínimo de representatividade para ocuparem cadeiras no Congresso Nacional.

Ao contrário sensu deste caminho, buscando desconstituir toda a importância dos Partidos Políticos para uma democracia representativa salutar, insurge-se no Senado Federal a PEC 6/2015 do Senado Federal, a qual busca permitir candidaturas avulsas de vinculação partidária, exigindo apenas o requisito de $1 \%$ (um por cento) das assinaturas da circunscrição eleitoral para o registro perante o Tribunal Superior Eleitoral (SENADO FEDERAL, 2017). Essa Proposta de Emenda à Constituição representa uma total desconstrução do sistema partidário, uma vez que a base de relações entre o Poder Executivo e Legislativo se dá a partir dos partidos políticos, bem como são eles que possuem a capacidade de mudar o estado das coisas no âmbito político a médio e longo prazo. Permitir candidaturas avulsas é personalizar a política e, acima de tudo, marginalizar aqueles que são a base da política programática no país. 


\section{CONCLUSÃO}

Ao cabo deste trabalho necessário se fazer algumas considerações sobre o cenário que perpassa a democracia representativa no Brasil, os escândalos de corrupção desvelados no âmbito da operação Lava-Jato e a possibilidade de adoção da Cláusula de Barreira Partidária no Brasil enquanto um dos caminhos para o melhoramento da democracia representativa, especialmente visando formar uma nação politicamente mais estável, pautada nos valores erigidos a partir da Constituição da República Federativa do Brasil de 1988.

O Brasil conta atualmente com 35 (trinta e cinco) partidos políticos em funcionamento com registro perante o TSE e outros 63 (sessenta e três) em processo de formação perante a corte eleitoral, o que sem dúvidas atrapalha a democracia representativa devido a fragmentação excessiva do Poder Legislativo. Restou demonstrada nesta pesquisa a necessidade de um patamar mínimo de representatividade, capaz de justificar o direito de um partido político em utilizar da estrutura de funcionamento parlamento no Congresso Nacional.

A implementação da Cláusula de Barreira na Alemanha conduziu o país a uma estabilidade política, garantindo a exclusão do processo político das minorias extremistas partidárias. Assim, a nação Alemã hoje conta com solidificados 6 (seis) partidos políticos, os quais possuem vertentes ideológicas e posições muito claras frente a população, oferecendo aos cidadãos reais opções de escolha. Aos críticos que entendem que a Cláusula de Barreira excluiria a igualdade de chances de ascensão ao poder dos pequenos partidos políticos, a experiência Alemã demonstra justamente o contrário, sendo que por diversas vezes os pequenos já conseguiram vencer a cláusula de barreira.

O excesso de partidos nanicos no Brasil torna muito difícil a cada ano a formação das bancadas de apoio no Legislativo e, consequentemente, gera um executivo instável, o qual caso se recuse a negociar com os pequenos partidos sofre as consequências da falta de apoio político. A redução do número de partidos políticos no Brasil é necessária para o sucesso do presidencialismo de coalizão, sendo impossível o sucesso de um governo sem forte apoio no Congresso Nacional.

A adoção no Brasil da Cláusula de Barreira é um ponto importantíssimo para ser adotado no Brasil por meio de Proposta de Emenda à Constituição, já que o Supremo Tribunal Federal entendeu pela inconstitucionalidade da Cláusula de Barreira por meio de legislação ordinária. Adotar a Cláusula de Barreira Partidária no Brasil não é negar aos pequenos a possibilidade de participar do processo político decisório, mas apenas de garantir a população um mínimo de representatividade social capaz de justificar sua existência e direito aos recursos públicos do fundo partidário. Melhorar a representatividade, diminuindo a quantidade de partidos políticos facilitaria a escolha do eleitor, o qual poderá conhecer o programa de cada partido que busca o seu voto.

Por fim, importante destacar que a PEC 282/2016 do Senado Federal representa um importante avanço nesse sentindo, instituindo uma Cláusula de Barreira mínima de 3\% (três por cento) dos votos nacionais, abaixo da Cláusula de Barreira Alemã, atualmente em 5\% (cinco por cento). No mais, tal Proposta de Emenda à Constituição garantiria aos candidatos eleitos abaixo da cláusula de barreira as opções de: a) exercerem seu mandato sem acesso à estrutura de funcionamento parlamentar no Congresso Nacional e participação proporcional nas comissões ou, b) filiar-se a outro partido político que tenha atingido o mínimo exigido na cláusula; diferentemente do Direito Alemão que exclui totalmente do Parlamento aqueles que não a atingiram. Dessa forma, a PEC 282/2016 é um importante avanço para o país, a qual refletirá uma melhor governabilidade e partidos políticos mais fortes para o futuro. 


\section{REFERÊNCIAS}

ABRANCHES, Sérgio Henrique Hudson de. Presidencialismo de coalizão: o dilema Institucional brasileiro. Revista de Ciências Sociais, Rio de Janeiro, n. 31, p. 5-34, 1988.

AVRITZER, Leonardo. Impasses da democracia no Brasil. 1. ed. Rio de Janeiro: Civilização Brasileira, 2016.

BOBBIO, Norberto. O futuro da democracia. Uma defesa das regras do jogo. Tradução: Marco Aurélio Nogueira. Rio de Janeiro: Paz e Terra, 1986.

BONAVIDES, Paulo. Ciência Política. 10. ed. São Paulo: Malheiros, 2001.

BRASIL. Câmara dos Deputados. PEC 282/2016. Disponível em: $<$ http://www.camara.gov.br/proposicoesWeb/fichadetramitacao?idProposicao=2118401> Acesso em 10/Jul/2017.

Senado Federal. PEC 07/2015. Disponível em: <https://www25.senado.leg.br/web/atividade/materias/-/materia/119631> Acesso em 08/08/2017. - Supremo Tribunal Federal. Ação Direito de Inconstitucionalidade $n^{\circ}$ 5.081/DF. Procuradoria Geral da República. Tribunal Superior Eleitoral. Relato: Ministro Luís Roberto Barroso. Brasília, DF, 27 de maio de 2015. Disponível em: <http://www.stf.jus.br/arquivo/cms/noticiaNoticiaStf/anexo/ADI5081.pdf >. Acesso em 11/07/2017.

- Supremo Tribunal Federal. Ação Direta de Inconstitucionalidade $n^{\circ}$ 1.351/DF. Partido Socialista Cristão. Congresso Nacional. Relator: Ministro Marco Aurélio. Brasília, DF, 7 de dezembro de 2006. Brasília. Disponível em: <http://www.stf.jus.br/arquivo/informativo/documento/informativo451.htm\#Partidos Políticos e Cláusula de Barreira - 1>. Acesso em: 12 jul. 2017.

Tribunal Superior Eleitoral. Partido em Formação. Disponível em: <http://www.tse.jus.br/partidos/partidos-politicos/partido-em-formacao> Acesso em 09/08/2017.

- Tribunal Superior Eleitoral. Partidos políticos registrados no TSE. Disponível em: <http://www.tse.jus.br/partidos/partidos-politicos/registrados-no-tse> Acesso em 08/ago/2017.

CAGGIANO, Monica Herman. O sistema eleitoral brasileiro: eleições gerais 2010 e eleições municipais 2012: o cenário eleitoral e sua anatomia. Revista de Direito Brasileira, Florianópolis, ano 2, n. 2, p. 399-423, jan./jun. 2012. Disponível em: <http://www.rdb.org.br/ojs/index.php/rdb/article/view/86> Acesso em 16/set/2017.

CASTRO, Mônica Mata Machado de. Cláusula de Barreira. In: AVRITZER, Leonardo; ANASTASIA, Fátima (Org.). Reforma política no Brasil. Belo Horizonte: Ufmg, 2006. p. 188191.

COMPARATO, Fábio Konder. Para viver a democracia. São Paulo: Brasiliense, 1989.

DUVERGER, Maurice. Os Partidos Políticos. Rio de Janeiro: Zahar, 1970.

FERREIRA FILHO, Manoel Gonçalves. A democracia no limiar do século XXI. São Paulo: Saraiva, 2001.

, Manoel Gonçalves. Curso de Direito Constitucional. 38. ed. São Paulo : Saraiva, 2012. 
, Manoel Gonçalves. Os partidos nas Constituições democráticas. Revista Brasileira de Estudos Políticos, Belo Horizonte, 1966.

FLEURY, Sônia. Iniciativa Popular. In: AVRITZER, Leonardo; ANASTASIA, Fátima (Org.). Reforma política no Brasil. Belo Horizonte: Ufmg, 2006. p. 94-98.

FOLHA DE SÃO PAULO. Delator da JBS diz ter pago propina a 1.829 políticos eleitos. Disponível em <http://www1.folha.uol.com.br/poder/2017/05/1885698-delator-da-jbs-diz-terpago-propina-a-1829-politicos-eleitos.shtml> Acesso em 02/mai/2017

FONSECA, Rafaela Aparecida. LACERDA, Josiane Auxiliadora. PEREIRA, José Roberto. A Crise da Democracia Representativa e o Voto Distrital como Alternativa. Direito, Estado e Sociedade, Rio de Janeiro, n. 44, p.142-143, 2014.

GIL, Antonio Carlos. Métodos e técnicas de pesquisa social. 6. Ed. São Paulo: Atlas, 2008.

GOMES, José Jairo. Direito eleitoral. 12. ed. São Paulo: Atlas, 2016.

LEÃO VIANA, João Paulo Saraiva. A cláusula de barreira na Alemanha. Estudos Eleitorais, v. 2, n. 3, p.2-21, mai./ago. 2006. Disponível em: <http://bibliotecadigital.tse.jus.br/xmlui/handle/bdtse/1188> Acesso em 08/ago/2017.

MANFREDINI, Karla M. Democracia Representativa Brasileira: O Voto Distrital Puro Em Questão. Florianópolis, 2008.

MENEZES, Aderson. Teoria Geral do Estado. Rio de Janeiro: Forense, 1999.

MEU CONGRESSO NACIONAL. Doações a partidos políticos pelas empresas relacionadas na Operação Lava Jato. Disponível em <http://meucongressonacional.com/lavajato/partidos> acesso em 02/mai/2017.

MEZZAROBA, Orides. A representação política na era da informação e o espaço reservado ao povo. In: ROVER, Aires José (ed). Inclusão Digital e governo eletrônico. Zaragoza: Prensas Universitarias de Zaragoza, 2008.

MEZZAROBA, Orides. Introdução ao Direito Partidário Brasileiro. Rio de Janeiro: Lumen Juris, 2003.

MICHAELIS. Moderno Dicionário da Língua Portuguesa. Disponível em: $<\mathrm{http}: / /$ michaelis.uol.com.br/busca? $\mathrm{r}=0 \& \mathrm{f}=0 \& \mathrm{t}=0 \&$ palavra=camarilha $>$ Acesso em 12/jul/2017.

MORAES, Alexandre de. Direito Constitucional. 24. Ed. São Paulo: Atlas, 2009.

MÜLLER, Friedrich. Quem é o povo? A questão fundamental da democracia. $3^{\mathrm{a}}$ ed. São Paulo: Editora Max Limonad, 2003.

NICOLAU, Jairo. Sistemas Eleitorais. 5. Ed. Rio de Janeiro: Editora FGV, 2004. 
NOGUEIRA FILHO, Octaciano da Costa. Sistemas políticos e o modelo brasileiro. Brasília: Senado Federal, 2007.

NOVELLI, Ana Lucia Romero. As sondagens de opinião como mecanismo de participação da sociedade. In: kunsch, Margarida Maria Krohling (org.). Comunicação pública, sociedade e cidadania. São Caetano do Sul: Difusão, 2011, p.245.

OLIVEIRA, Fábio Cesar dos Santos. Democracia e internet: A revolução digital e os desafios à representação política. Revista de Informação Legislativa, v. 50, n. 199, p.143-161, jul./set. 2013. Disponível em: <http://www2.senado.leg.br/bdsf/handle/id/502922〉. Acesso em: 29 jun. 2017.

PONTES, Roberto Carlos Martins; Holthe, Leo Oliveira Van. O sistema eleitoral Alemão após a Reforma de 2013 e a viabilidade de sua adoção no Brasil. Câmara dos Deputados, Consultoria Legislativa. Disponível em <http://bd.camara.gov.br/bd/handle/bdcamara/22079\#> Acesso em 08/Ago/2017.

REIS, Wanderley. Partidos e políticos são imprescindíveis, diz Wanderley Reis. Disponível em<http://www1.folha.uol.com.br/paywall/login.shtml?http://www1.folha.uol.com.br/poder/201 7/04/1874839-partidos-e-politicos-sao-imprescindiveis-diz-wanderley-reis.shtml> acesso em 29/mai/2017.

SARLET, Ingo Wolfgang. A eficácia dos direitos fundamentais: uma teoria geral dos direitos fundamentais na perspectiva constitucional. 11. Ed. Porto Alegre: Livraria do Advogado Editora, 2012.

SARTORI. Giovanni. Partidos e sistemas partidários. Coleção Pensamento Político, $\mathrm{n}^{\circ}$ 43, Rio de Janeiro: Zahar, Brasília: Universidade de Brasília, 1982.

SCHUMPETER, Joseph. Capitalismo, Socialismo e Democracia. Rio de Janeiro: Fundo de Cultura, 1961.

SILVA, Luís Virgílio Afonso da. Sistemas eleitorais: tipos, efeitos jurídico-políticos e aplicação ao caso brasileiro. $1^{a}$ Edição. São Paulo: Malheiros Editores, 1999.

STRECK, Lênio Luiz; DE MORAIS, José Luis Bolzan. Ciência política e teoria do estado. 8. ed. Porto Alegre: Livraria do Advogado Editora, 2014.

TAVARES, André Ramos. A sociedade perante as mudanças do marco político e eleitoral brasileiro: entre aprimoramento referendário e experimentalismo fraudulento. Revista de Direito Brasileira, Florianópolis, v. 2, n. 2, p.381-397, jun. 2012. Disponível em: <http://www.rdb.org.br/ojs/index.php/rdb/article/view/85>. Acesso em: 16 ago. 2017.

TAVARES, José Antônio Giusti. A medição dos partidos na democracia representativa brasileira: o sistema partidário na consolidação da democracia brasileira. Brasília: Instituto Teotônio Vilela, 2003. 